\title{
Expression and purification of a human anti-cyclin D1 single-chain variable fragment antibody AD5 and its characterization
}

\author{
YAN WU $^{1}$, DESHENG ZOU ${ }^{1}$, YUHUA CAO ${ }^{1}$, NANNAN YAO ${ }^{1}$, \\ JUNYE WANG $^{1}$, WENHAN WANG ${ }^{1}$, HONGYU JIANG ${ }^{3}$ and GUIYING LI ${ }^{1,2}$ \\ ${ }^{1}$ Key Laboratory for Molecular Enzymology and Engineering of the Ministry of Education, \\ ${ }^{2}$ National Engineering Laboratory for AIDS Vaccine, College of Life Science, Jilin University, Changchun, Jilin 130012; \\ ${ }^{3}$ Department of General Internal Medicine, The First Hospital of Jilin University, Changchun, Jilin 130021, P.R. China
}

Received July 15, 2013; Accepted October 2, 2013

DOI: 10.3892/ijmm.2013.1523

\begin{abstract}
Cyclin D1 plays an important role in cell cycle progression. Increasing evidence indicates that cyclin D1 is overexpressed in the majority of tumor cells and has become a potential target for tumor therapy. However, little research has been done on the specific inhibition of cyclin D1 for cancer therapy. With the rapid development of the phage display antibody library technique, single-chain variable fragment $(\mathrm{scFv})$ antibodies have emerged, which have tremendous application prospects in cancer therapy and diagonosis. In this study, a human scFv binding specifically to cyclin D1 (AD5) that was derived from a human semi-synthetic $\mathrm{scF}$ v phage library was expressed in the soluble form in Escherichia coli (E. coli) HB2151 cells. To characterize AD5, soluble AD5 was purified successfully through ammonium sulfate precipitation and affinity chromatography from the culture supernatant of AD5/HB2151. ELISA assay revealed that purified soluble AD5 could specifically bind to human recombinant cyclin D1 with approximately $(1.19 \pm 0.056) \times 10^{7} \mathrm{M}^{-1}$ affinity constant and showed approximately $52 \%$ competitive inhibition with the anti-cyclin D1 polyclonal antibody for binding to cyclin D1 in vitro. These results suggest that the $\mathrm{scFv}$ antibody against cyclin D1 may be a novel potential tool for targeting cyclin D1 in cancer therapy and diagnosis.
\end{abstract}

Correspondence to: Professor Guiying Li, Key Laboratory for Molecular Enzymology and Engineering of the Ministry of Education, College of Life Science, Jilin University, 2699 Qianjin Street, Changchun, Jilin 130012, P.R. China

E-mail: ligy@jlu.edu.cn

Professor Hongyu Jiang, Department of General Internal Medicine, The First Hospital of Jilin University, 71 Xinmin Street, Changchun, Jilin 130021, P.R. China

E-mail: jiang_hy@jlu.edu.cn

Key words: cyclin D1, single-chain variable fragment, purification, characterization, cancer

\section{Introduction}

Cell cycle progression in eukaryotic organisms is primarily controlled by cyclin-dependent kinases (CDKs), cyclins and CDK inhibitors. Cyclin as a regulatory subunit forms a heterodimeric complex with corresponding CDKs. The activated cyclin/CDK complex phosphorylates a set of substrates required for continued cell cycle progression and triggers transition to distinct cell cycle phases. During the G1 phase, D-type cyclins (D1, D2 and D3) accumulate in response to mitogenic stimulation and form active kinase complexes with their catalytic partners, CDK4 and CDK6 (1). Cyclin D1 plays a vital role in promoting the G1/S transition of the cell cycle by inactivating the retinoblastoma protein $(\mathrm{Rb})$ through superphosphorylation. Phosphorylated Rb liberates E2F and other Rb-bound transcription regulators, leading to the activation of $\mathrm{S}$ phase-specific genes $(1,2)$. The deregulation of cyclin D1 may promote the development of tumors. The amplification of the cyclin D1 gene and the overexpression of cyclin D1 proteins have been reported in a large proportion of human cancers, including human breast, lung and gastrointestinal malignancies. For example, approximately $15-20 \%$ of human mammary carcinomas contain the amplification of the cyclin D1 gene, while cyclin D1 is overexpressed at the mRNA and protein level in $>50 \%$ of breast cancers (3-6). Furthermore, cyclin D1 is required for tumor initiation and maintenance, as the genetic ablation of murine cyclin D1 has been shown to result in resistance to ErbB2-driven mammary adenocarcinomas, and the ubiquitous shutdown of cyclin D1 in mice bearing ErbB2driven mammary carcinomas has been shown to trigger tumor cell senescence (7-9). The gene encoding cyclin D1 is an oncogene and represents the second most frequently amplified locus in a diverse set of human cancer genomes, as revealed by recent findings $(10,11)$. Due to its frequent deregulation and essential requirement in cancer, cyclin D1 has been the focus of cancer research and the potential target of drugs designed for cancer treatment $(3,5,8,11)$. However, little research has been done on the specific inhibition of cyclin D1 for cancer therapy.

Antibodies have been shown to have a number of applications in biotechnology and clinical medicine, particularly in the field of oncology, due to their high specificity and affinity binding to target antigens $(12,13)$. With the development of anti- 
body engineering technology, a number of novel antibodies have been generated, including single-chain variable fragment ( $\mathrm{scFv}$ ) antibodies $(14,15)$. scFv antibodies have tremendous potential in cancer prevention, diagnosis and therapy due to their specific binding affinity to the antigen, their small size, superior biodistribution and blood clearance, and can be easily engineered or modified to create intrabodies $(12,13,16-18)$. Recently, we constructed an anti-cyclin D1 intrabody (AD5N) by linking a nuclear localization signal sequence to the human anti-cyclin D1 scFv AD5 coding gene obtained from the human semi-synthetic scFv phage library. The expression of AD5N inhibited the growth and proliferation of HeLa and MCF-7 cells $(19,20)$. Our previous studies indicated that the $\mathrm{scFv}$ antibodies may be a powerful tool which can be used to block the function of overexpressed cyclin D1. In order to achieve the optimal knockout of cyclin D1 by the anti-cyclin D1 scFv antibody, further understanding the characteristics of this $\mathrm{ScFv}$ is required.

In this study, a human scFv antibody against cyclin D1 (AD5) that was derived from a human semi-synthetic scFv phage library was expressed in the soluble form in Escherichia coli $(E$. coli) HB2151 cells. The purification and identification of AD5 was conducted successfully by using affinity chromatography, ELISA and western blot analysis. Its binding affinity to cyclin D1 was measured by non-competitive enzyme immunoassay. This study lays the foundation for the use of anti-cyclin D1 scFv antibody for a variety of basic research and potential gene therapy strategies.

\section{Materials and methods}

Materials. The helper phage, VCSM13, the E. coli strains, HB2151 and XL1-Blue, ovalbumin (OA) and tumor necrosis factor $\alpha(\mathrm{TNF} \alpha)$ were generously provided by Professor Yan Wang (Navy General Hospital, Beijing, China). Phagemid AD5 encoding anti-cyclin D1 scFv antibody and V5 tag was screened from a human semi-synthetic $\mathrm{scFv}$ phage library (generously provided by Professor Yan Wang) (21). The antibody against cyclin D1 was purchased from Santa Cruz Biotechnology (Santa Cruz, CA, USA). The antibody against V5 tag was purchased from Invitrogen (Carlsbad, CA, USA). The antibody against His tag was purchased from HangZhou HuaAn Biotechnology Company (Hangzhou, China). Horseradish peroxidase (HRP)-conjugated IgG was purchased from the Protein Tech Group (Chicago, IL, USA). The HRP-conjugated anti-M13 antibody, HisTrap HP colomns and PD-10 desalting columns were purchased from Amersham Pharmacia Biotech, Inc. (Piscataway, NJ, USA). Bovine serum albumin (BSA) and Coomassie blue R-250 were purchased from Sigma (St. Louis, MO, USA).

Binding activity of phage antibodies with cyclin D1. E. coli XL1-Blue competent cells were transformed by the phagemid AD5 and were then allowed to grow on SB agar plates containing $50 \mu \mathrm{g} / \mathrm{ml}$ ampicillin and $10 \mu \mathrm{g} / \mathrm{ml}$ tetracycline overnight at $37^{\circ} \mathrm{C}$. Ampicillin- and tetracycline-resistant colonies carrying phagemid AD5 (AD5/XL1-Blue) were grown in SB medium containing $50 \mu \mathrm{g} / \mathrm{ml}$ ampicillin and $10 \mu \mathrm{g} / \mathrm{ml}$ tetracycline at $37^{\circ} \mathrm{C}$ to optical density (OD) ${ }_{600} 0.5$. VCSM13 helper phage were added to the culture of $E$. coli AD5/XL1-Blue, followed by incubation without shaking at $37^{\circ} \mathrm{C}$ for $1 \mathrm{~h}$. The infected cells were then incubated with shaking overnight at $30^{\circ} \mathrm{C}$ under $30 \mu \mathrm{g} / \mathrm{ml}$ kanamycin resistance. The culture supernatants containing phage antibody AD5 were obtained by centrifugation and were then subjected to the analysis of binding activity by ELISA assay in the microtiter plates (Nunc) coated with purified cyclin D1 (22) as antigen or OA, TNFa and BSA as irrelevant antigens controls. VCSM13 helper phage was added to the microtiter plates (Nunc) coated with purified cyclin D1, OA, TNF $\alpha$ and BSA instead of the culture supernatants containing phage antibody AD5 to verify the binding specificity. Following incubation with the above phage supernatants and HRP-conjugated anti-M13 antibody, the reaction was developed by adding $o$-phenylenediamine (OPD) and monitored by a microplate reader (Thermo Labsystems, Waltham, MA, USA) at wavelengths of $492 \mathrm{~nm}$.

Expression and identification of soluble AD5. Amber nonsuppressive $E$. coli $\mathrm{HB} 2151$ cells were infected by the above phage clones to obtain $E$. coli AD5/HB2151 that can express the soluble AD5. E. coli AD5/HB2151 cells were stimulated by isopropyl $\beta$-D-1-thiogalactopyranoside (IPTG) to induce the expression of soluble AD5. The culture supernatant of AD5/HB2151 was collected by centrifugation after IPTG induction overnight at $30^{\circ} \mathrm{C}$ shaking. The expression and binding activity of soluble AD5 to cyclin D1 were conducted by ELISA assay in the microtiter plates (Nunc) coated with purified human recombinant cyclin D1, as previously described (22) as antigen or OA, TNF $\alpha$ and p16 as irrelevant antigens controls, followed by sequential incubation with the above culture supernatant of AD5/HB2151, V5-tag antibody and HRP-conjugated IgG. The reaction was developed by adding OPD and monitored by a microplate reader (Thermo Labsystems) at wavelengths of $492 \mathrm{~nm}$. The microtiter plates (Nunc) coated with the above proteins were incubated with PBST (0.05\% Tween-20 in PBS) containing 1\% of BSA instead of anti-V5-tag antibody as the negative controls (NC).

Purification of soluble AD5. The culture supernatant of AD5/HB2151 stimulated by IPTG overnight at $30^{\circ} \mathrm{C}$ was supplemented with various concentration of solid ammonium sulphate and stirred at $4^{\circ} \mathrm{C}$ for $5 \mathrm{~h}$. The solution was then centrifuged and the pellet was retained. The pellet containing AD5 was dissolved with ice-cold PBS and dialyzed in PBS buffer overnight at $4^{\circ} \mathrm{C}$. Following centrifugation, the clear supernatant was collected and applied to affinity chromatography with His Trap HP column equilibrated with binding buffer $(50 \mathrm{mM}$ phosphate-buffer, $\mathrm{pH} 7.4,500 \mathrm{mM} \mathrm{NaCl}, 10 \mathrm{mM}$ imidazole). The column was then washed sequentially with binding buffer, washing buffer (50 mM phosphate-buffer, $\mathrm{pH} 7.4,500 \mathrm{mM}$ $\mathrm{NaCl}, 40 \mathrm{mM}$ imidazole) and eluting buffer $(50 \mathrm{mM}$ phosphate-buffer, $\mathrm{pH} 7.4,500 \mathrm{mM} \mathrm{NaCl}, 500 \mathrm{mM}$ imidazole). The purification of AD5 was examined by running an aliquot of the collected samples on $12 \%$ SDS-polyacrylamide gel electrophoresis (PAGE) and then stained with Coomassie blue R-250. The purified AD5 was desalted by PD-10 desalting columns. The AD5 proteins were kept at $-80^{\circ} \mathrm{C}$ after the determination of the concentration by Bradford assay.

Immunoblotting. The samples were subjected to SDS-PAGE and the separated proteins were electrophoretically trans- 
ferred onto nitrocellulose membranes (Bio-Rad, Hercules, CA, USA). Non-specific binding was blocked with PBST (0.05\% Tween-20 in PBS) containing 5\% non-fat milk for $1 \mathrm{~h}$ at room temperature. The membranes were then incubated overnight at $4^{\circ} \mathrm{C}$ with antibodies against His tag or V5 tag in PBST containing $1 \%$ non-fat milk at the dilutions specified by the manufacturers. Following 3 washes with PBST, the membranes were then incubated with the HRP-conjugated secondary antibodies at 1:5,000 dilution in PBST containing $1 \%$ non-fat milk for $1 \mathrm{~h}$ at room temperature. The membranes were then washed 3 times with PBST and the protein bands were detected using the western blotting detection system.

Competition ELISA. Cyclin D1 (1-10 $\mu \mathrm{g} / \mathrm{ml})$ was coated onto the surface of wells in a 96-well microtitre plate (Nunc) overnight at $4^{\circ} \mathrm{C}$. Following blocking, $50 \mu \mathrm{l}$ of AD5 $(10 \mu \mathrm{g} / \mathrm{ml}$ in PBST containing 3\% non-fat milk) and an equal volume of rabbit anti-cyclin D1 antibody (1:1,000 dilution in PBST containing $3 \%$ non-fat milk) were added to each well as the test group. Wells with only $100 \mu \mathrm{l}$ of rabbit anti-cyclin D1 antibody (1:2,000 dilution in PBST containing 3\% non-fat milk) were used as the positive controls. A total of $50 \mu \mathrm{l}$ of OA or TNF $\alpha(10 \mu \mathrm{g} / \mathrm{ml}$ in PBST containing $3 \%$ non-fat milk) and equal volume of rabbit anti-cyclin D1 antibody $(1: 1,000$ dilution in PBST containing 3\% non-fat milk) were added to each well to examine the specific binding between AD5 and cyclin D1. After $2 \mathrm{~h}$ of incubation at $37^{\circ} \mathrm{C}$, the plate was washed with PBST followed by detection using HRP-conjugated goat anti-rabbit antibody as described above. The reaction was developed by the addition of OPD and monitored by a plate reader (Thermo Labsystems) at wavelengths of $492 \mathrm{~nm}$. The inhibition rate of AD5 to anti-cyclin D1 polyclonal antibody was calculated using the following formula: inhibition rate $(\%)=\left(\mathrm{OD}_{492}\right.$ of the positive control - $\mathrm{OD}_{492}$ of the test group $) /$ $\mathrm{OD}_{492}$ of the positive control $\times 100 \%$.

Determination of affinity. Non-competitive ELISA was used to determine the affinity of AD5 to cyclin D1 as previously described (23). Briefly, a 96-well plate was coated with serial dilutions of recombinant human cyclin D1 protein at $4{ }^{\circ} \mathrm{C}$ overnight. Four different concentrations of cyclin D1 were used. Following incubation with serial dilutions of AD5, the plate was sequentially incubated with anti-V5 tag antibody and HRP-conjugated goat anti-mouse IgG. The binding reaction was detected by the addition of OPD and monitored by a microplate reader (Thermo Labsystems) at wavelengths of $492 \mathrm{~nm}$. Three parallel wells were used in a plate for each concentration of cyclin D1 and AD5. The amount of AD5 (Ab' or Ab) adherent to cyclin D1 (Ag' or Ag) on the plate was reflected by the enzyme product measured by $\mathrm{OD}_{492}$. Sigmoid curves were made from OD vs. the logarithm of total $\mathrm{Ab}$ added to the well. The affinity constant $\left(K_{\text {aff }}\right)$ of the antibody was calculated using the following formula: $K_{\mathrm{aff}}=(\mathrm{n}-1) /\left(\mathrm{n}\left[\mathrm{Ab}^{\prime}\right]-[\mathrm{Ab}]\right)$ $\left\{\mathrm{n}=[\mathrm{Ag}] /\left[\mathrm{Ag}^{\prime}\right],[\mathrm{Ab}]\right.$ and $\left[\mathrm{Ab}^{\prime}\right]$ represent the concentration of antibody corresponding to half the maximum OD value (OD-100) calculated with a computerized nonlinear regression method for plates coated with $[\mathrm{Ag}]$ and $\left[\mathrm{Ag}^{\prime}\right]$, respectively\}.

Statistical analysis. All conditions were performed in triplicate, and the reported values are representative of 3 independent experiments. All values are expressed as the means \pm SD of 3 parallel measurements. Data were analyzed using the Student's t-test and values of $\mathrm{P}<0.05$ were considered to indicate statistically significant differences.

\section{Results}

AD5 antibody binds specifically to cyclin D1. When the phagemids were rescued by helper phages derived from M13 (VCSM13), the scFv-gene was fused with gene III of the M13 phage and expressed as a $\mathrm{scFv}$ at the tip of the phage particle. This is convenient for the detection of the specific binding of an antibody to a protein. In this study, the phagemid AD5 was transferred into $E$. coli XL1-Blue cells and was then rescued by helper phage VCSM13. The ELISA results demonstrated that the culture supernatants containing phage antibody AD5 showed selective binding to cyclin D1. As illustrated in Fig. 1A, the absorbance at $492 \mathrm{~nm}$ for AD5 phage binding to cyclin D1 was $0.980 \pm 0.044$, which was significantly higher than the irrelevant antigen control groups $(\mathrm{P}<0.01)$. However, compared with the AD5 phage binding activity, the absorbance at $492 \mathrm{~nm}$ for the negative control VCSM13 helper phage binding to cyclin D1 was distinctly lower (0.100 \pm 0.005 ; $\mathrm{P}<0.01)$. Moreover, the VCSM13 helper phage showed a very similar binding activity to cyclin D1 and the irrelevant antigen control groups $(\mathrm{P}>0.05)$. This suggests that the phage antibody AD5 has specific binding affinity to cyclin D1.

In order to identify the binding affinity of soluble AD5 to cyclin D1, amber non-suppressive $E$. coli HB2151 cells were transduced with the AD5 phage clones and stimulated by IPTG to induce the expression of soluble AD5. The ELISA results revealed a significantly higher binding affinity for soluble AD5 to cyclin D1. As shown in Fig. 1B, the absorbance at $492 \mathrm{~nm}$ for soluble AD5 to cyclin D1 was $1.43 \pm 0.0785$ compared with $0.096 \pm 0.006,0.105 \pm 0.007$ and $0.045 \pm 0.011$ to $\mathrm{TNF} \alpha(\mathrm{P}<0.01)$, OA $(\mathrm{P}<0.01)$ and p16 $(\mathrm{P}<0.01)$, respectively. For the negative controls, although it showed a much lower value than that for soluble AD5 to cyclin D1 $(\mathrm{P}<0.01)$, there was no siginificant difference among the lower absorbance to the above proteins incubated with BSA instead of anti-V5-tag antibody ( $\mathrm{P}>0.05)$.

Purification of soluble AD5. Soluble AD5 was expressed in E. coli AD5/HB2151 and secreted into the culture medium. To purify soluble AD5, the separation of crude proteins was first conducted by ammonium sulfate precipitation from the culture supernatant of E. coli AD5/HB2151 (Fig. 2). The gradient ammonium sulfate precipitation indicates that a $40 \%$ saturation of ammonium sulfate is opitmal, which can not only eliminate contaminations of most other proteins but can also yield more partially purified proteins for the next purification (data not shown). Therefore, $40 \%$ ammonium sulfate precipitation provides the optimal conditions for further purification. The crude proteins were then adsorbed to His Trap HP column. SDS-PAGE analysis of the eluted fractions revealed that a single band of approximately $33 \mathrm{kDa}$ was detected (Fig. 2).

Since AD5 contains a His tag at N-terminal and V5 tag at C-terminal, AD5 as identified by western blot analysis using anti-V5 or anti-His antibody immunoreactivity. As shown in Fig. 3A, the western blot images displayed that following induction by IPTG, cell lysis of $E$. coli AD5/HB2151, the 
A

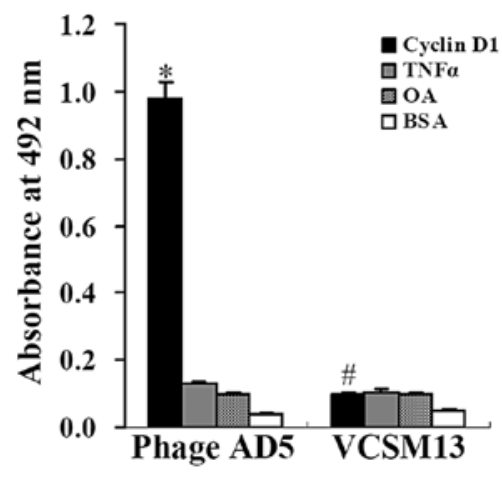

B

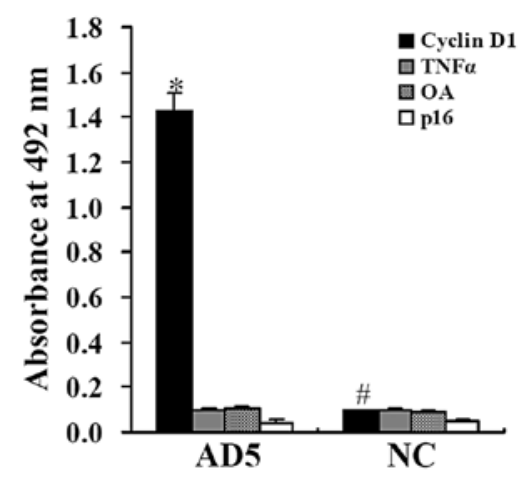

Figure 1. The binding affinity of the phage antibody and soluble single-chain variable fragment (scFv) antibody AD5 to cyclin D1 by ELISA. (A) Detection of antigen binding affinity of phage antibody AD5. Wells coated with equal amounts of recombinant human cyclin D1 or irrelevant antigens were sequentially incubated with phage-infected $E$. coli XL1-Blue culture supernatants containing AD5 phage particles and HRP-conjugated anti-M13 antibody to conduct ELISA assay. VCSM13 helper phage instead of the culture supernatants containing phage antibody AD5 were used as the negative control. ("P $<0.01$ vs. corresponding irrelevant protein controls or VCSM13 group, ${ }^{\#} \mathrm{P}>0.05$ vs. corresponding irrelevant protein controls). (B) Cyclin D1-binding activity of soluble scFv antibody AD5. Wells coated with equal concentrations of recombinant human cyclin D1 and the irrelevant proteins were sequentially incubated with phage-infected E. coli $\mathrm{HB} 2151$ culture supernatants containing soluble AD5, anti-V5 tag antibody and HRP-conjugated IgG to conduct ELISA assay. BSA instead of the culture supernatants containing soluble AD5 were used as the negative control (NC). $\left({ }^{*} \mathrm{P}<0.01\right.$ vs. corresponding irrelevant protein controls or $\mathrm{NC}$ group, ${ }^{\prime \prime} \mathrm{P}>0.05 \mathrm{vs}$. corresponding irrelevant protein controls). TNF $\alpha$, tumor necrosis factor $\alpha$; OA, ovalbumin; BSA, bovine serum albumin.

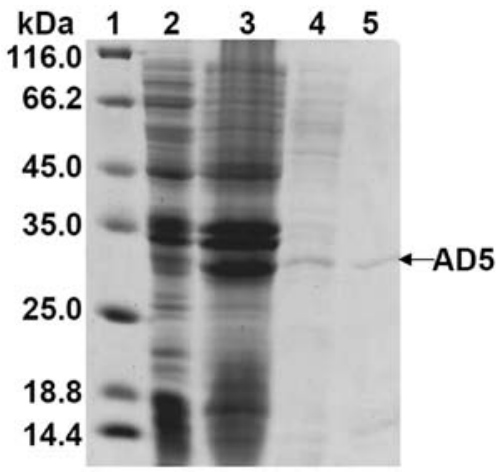

Figure 2. Expression and purification of soluble AD5. The samples were subjected to $12 \%$ SDS-PAGE. The separated proteins were then stained with Coomassie blue R-250 and photographed. Lane 1, protein molecular weight standards; lane 2, bacterial lysate of AD5/HB2151 without induction by IPTG; lane 3, bacterial lysate of AD5/HB2151 induced by IPTG; lane 4, culture supernatant of AD5/HB2151 induced by IPTG; lane 5, the purified AD5 by His Trap HP column.

culture supernatant of E. coli AD5/HB215 and purified AD5 protein all showed a clear protein band of approximately $33 \mathrm{kDa}$. The protein band was not detected in the cell lysis of $E$. coli AD5/HB2151 without IPTG induction. These results suggested that soluble AD5 was expressed in E. coli AD5/HB2151 cells, secreted into the culture supernatant and was purified successfully.

In order to examine the binding activity of purified AD5 to cyclin D1, an ELISA assay was performed. As shown in Fig. 3B, the absorbance at $492 \mathrm{~nm}$ for the purified AD5 to cyclin D1 was significantly higher than that of the irrelevant antigen BSA and the negative control $(\mathrm{NC})(\mathrm{P}<0.01)$. However there was no siginificant difference among the lower absorbance of BSA and the negative control $(\mathrm{P}>0.05)$.

AD5 competes with anti-cyclin D1 polyclonal antibody to bind to cyclin $D 1$. To detect the competitive inhibition ability of AD5 with the anti-cyclin D1 polyclonal antibody to bind to
A

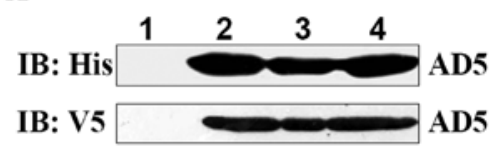

B

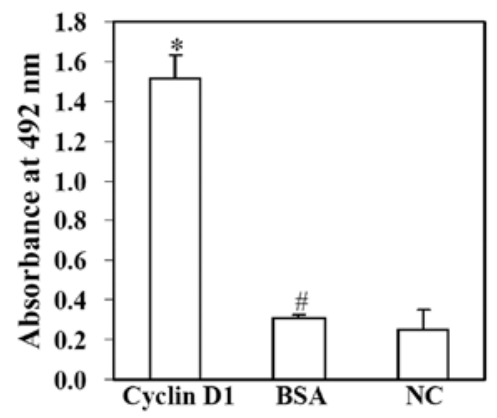

Figure 3. Identification of purified AD5. (A) Identification of purified AD5 by western blot analysis. The obtained proteins were subjected to $12 \%$ SDS-PAGE under reducing conditions. The seperated proteins were blotted onto a nitrocellulose membrane, blocked with 5\% non-fat milk, and probed with anti-V5 tag or anti-His tag mAb to detect AD5. Lane 1, bacterial lysate of AD5/HB2151 without induction by IPTG; lane 2, bacterial lysate of AD5/HB2151 induced by IPTG; lane 3, culture supernatant of AD5/ HB2151 induced by IPTG; lane 4, the purified AD5 by His Trap HP column. (B) Cyclin D1-binding activity of purified AD5. Wells coated with equal concentrations of recombinant human cyclin D1 and the irrelevant proteins [bovine serum albumin (BSA)] were sequentially incubated with purified AD5, anti-V5 tag antibody and HRP-conjugated IgG to conduct ELISA assay. Absence of purified AD5 were used as the negative control (NC). ( $\mathrm{P}<0.01$ vs. corresponding irrelevant protein controls or $\mathrm{NC}$ group, ${ }^{~} \mathrm{P}>0.05$ vs. corresponding $\mathrm{NC}$ group).

cyclin D1, competition ELISA experiments were conducted. As illustrated in Fig. 4, when cyclin D1 was incubated only with anti-cyclin $\mathrm{D} 1$ polyclonal antibody, the $\mathrm{OD}_{492}$ was $1.029 \pm 0.027$. Following incubation with anti-cyclin D1 polyclonal antibody mixture containing $\mathrm{AD} 5$, the $\mathrm{OD}_{492}$ was markedly reduced to 


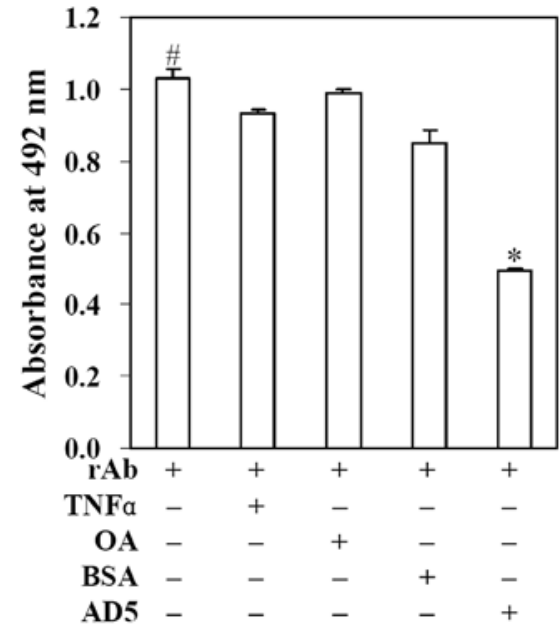

Figure 4. AD5 competes with the anti-cyclin D1 polyclonal antibody to bind to cyclin D1. Wells coated with equal amounts of recombinant human cyclin D1 were incubated with rabbit anti-cyclin D1 antibody (positive control) or equal volume mixture of rabbit anti-cyclin D1 antibody and irrelevant proteins (OA or TNF $\alpha$ or BSA) or AD5. ELISA assay was then performed by probing with HRP-conjugated goat anti-rabbit antibody and the addition of $o$-phenylenediamine (OPD). ( $\mathrm{P}<0.01$ vs. corresponding positive control or irrelevant protein controls, ${ }^{\prime} \mathrm{P}>0.05$ vs. corresponding irrelevant protein controls). TNF $\alpha$, tumor necrosis factor $\alpha$; OA, ovalbumin; BSA, bovine serum albumin.

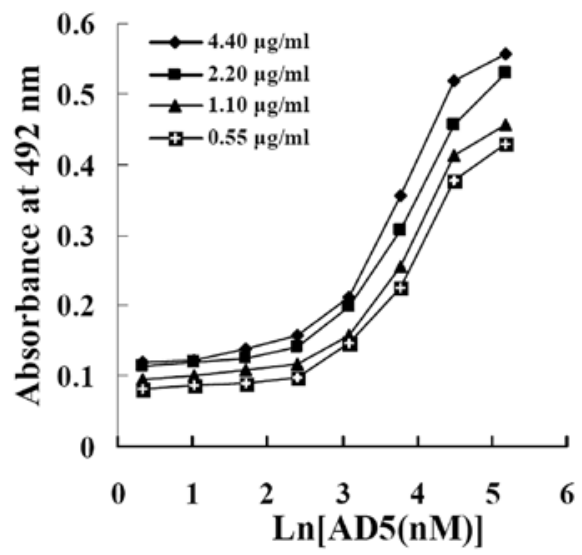

Figure 5. Determination of affinity constant of AD5. The measurement of AD5 affinity was based on non-competitive ELISA. The concentrations of cyclin D1 in the coating solution were 4.4, 2.2, 1.1 and $0.55 \mu \mathrm{g} / \mathrm{ml}$. Following incubation with serial dilutions of AD5 to conduct non-competitive ELISA assay, the AD5 concentration (nM) of every curve corresponding to half the maximum absorbance value was calculated according to the methods described in 'Materials and methods'. Then 6 affinity constants and the average affinity constants were acquired.

0.495 \pm 0.006 . However, when cyclin D1 was incubated with anti-cyclin D1 polyclonal antibody mixture containing the irrelevant antigens, TNF $\alpha, \mathrm{OA}$ or BSA, the $\mathrm{OD}_{492}$ was $0.930 \pm 0.013$, $0.990 \pm 0.009$ and $0.848 \pm 0.039$, respectively, which showed no significant difference compared with the positive control group ( $\mathrm{P}>0.05)$. These results indicated that AD5 significantly inhibited the binding between anti-cyclin D1 polyclonal antibody and cyclin $\mathrm{D} 1(\mathrm{P}<0.01)$. According to the above formula, we found that the inhibition rate was approximately $52 \%$. This suggests that AD5 competes with the anti-cyclin D1 polyclonal antibody to bind to cyclin D1.
Table I. Affinity calculated from the non-competitive ELISA curves of AD5 antibody against cyclin D1.

\begin{tabular}{lcccc}
\hline & \multicolumn{4}{c}{ Affinity $\left(\times 10^{7} \mathrm{M}^{-1}\right)$} \\
\cline { 2 - 5 } Antibody & $K_{\mathrm{n}=2}$ & $K_{\mathrm{n}=4}$ & $K_{\mathrm{n}=8}$ & Mean $\pm \mathrm{SD}$ \\
\hline AD5 & $1.10,1.27,1.16$ & $1.21,1.19$ & 1.18 & $1.19 \pm 0.06$
\end{tabular}

$K_{\mathrm{n}=2}$ is the collection of affinity calculated from every 2 curves differing in amount of coated cyclin D1 by 2-fold dilution. Analogized from this, $K_{\mathrm{n}=4}$ and $K_{\mathrm{n}=8}$ were calculated and listed above.

Affinity of AD5. The relative affinity constant of AD5 was measured by non-competitive enzyme immunoassay, as previously described by Beaty et $a l$, which is able to measure $K_{\text {aff }}$ by solid-phase EIA using serial dilutions of antigens (coating the plate) and antibody (23). According to the 4 concentrations of cyclin D1 $(4.40,2.20,1.10$ and $0.55 \mu \mathrm{g} / \mathrm{ml})$ coated onto the plates, 4 sigmoid curves were made from OD vs. the logarithms of AD5 concentrations added to the wells (Fig. 5). As shown in Table I, according to the curves and the formula, 6 affinity constants ( 3 for $\mathrm{n}=2,2$ for $\mathrm{n}=4$ and 1 for $\mathrm{n}=8$ ) were obtained for AD5. The mean affinity constant $\left(K_{\text {aff }}\right)$ of AD5 for cyclin D1 was approximately $(1.19 \pm 0.056) \times 10^{7} \mathrm{M}^{-1}$.

\section{Discussion}

Cyclin D1 is a component of the core cell cycle machinery. Cyclin D1 activates CDK4 and CDK6 and drives cell growth and proliferation. Its deregulation may promote the development of tumors $(3,5,8,9)$. Cyclin D1 may be a potential prognostic marker and a therapeutic target in cancer $(5,9,10,24)$. Although previous studies have indicated that the function of cyclin D1 is inhibited by using inhibitors to CDK4 $(8,9)$, this is not sufficient to block the activity of cyclin D1, as cyclin D1 has been reported to modulate the activity of several transcription factors independent of binding to CDK4 $(25,26)$. Therefore, there is a pressing need to develop inhibitory strategies targeting cyclin D1. Antibodies have been proven to be attractive anticancer agents due to their high specificity and affinity towards targeting antigens $(12,13)$. In this study, a human scFv antibody against cyclin D1 (AD5) that was derived from a human semi-synthetic scFv phage library was expressed in the soluble form in E. coli HB2151 cells. Soluble AD5 was isolated from culture supernatants by the saturation of ammonium sulfate precipitation at a concentration of $40 \%$, and purified successfully through the His Trap HP column. AD5 could specifically bind to human recombinant cyclin D1 with approximately $(1.19 \pm 0.056) \times 10^{7} \mathrm{M}^{-1}$ affinity constant and showed approximately $52 \%$ competitive inhibition with the anti-cyclin D1 polyclonal antibody for binding to cyclin D1. These results demonstrated that a human anti-cyclin D1 scFv antibody specifically binding to cyclin D1 was successfully prepared.

$\mathrm{scFv}$ antibodies have been successfully isolated and displayed in various expression systems, including $E$. coli cells $(27,28)$. Previous studies have demonstrated that the majority of $\mathrm{scFv}$ antibodies are expressed as insoluble inclusion bodies in the cytoplasm of E. coli cells (27-30). Although 
the inclusion bodies can easily be separated from the soluble proteins of host cells and increase the yield of the purified product, the inclusion bodies require denaturation and refolding, which increases the difficulty to produce active soluble scFv antibodies (27). To overcome this problem, a signal peptide is used to direct the secretion of the $\mathrm{scFv}$ antibodies to the periplasmic space and culture medium in soluble form (31). In this study, soluble $\mathrm{scFv}$ antibody was expressed in non-suppressive $E$. coli HB2151 bacteria cells. There is a succinic acid termination codon gene between the phage pIII gene and scFv gene. When the phage is infected into nonsuppressive E. coli HB2151, the succinic acid termination codon will be translated to the termination codon. Therefore, the $\mathrm{scFv}$ gene will not be expressed as a fusion protein with pIII in HB2151, but it will be expressed as the soluble protein and secreted into the periplasmic space and culture medium. In this study, after induction with IPTG, we found there was soluble anti-cyclin D1 scFv antibody (AD5) in the supernatant of culture medium by ELISA assay and western blot analysis. The active purified soluble AD5 was obtained successfully through affinity chromatography. Therefore, the expression system for soluble AD5 we applied in this study is certainly feasible.

Affinity of the antibody is a critical parameter that shows the ability of the antibody to bind to its antigen. scFv antibodies from either the semi-synthetic or naive antibody library generaly bind to their antigens with lower affinities, ranging from $10^{6}-10^{9} \mathrm{M}^{-1}$ (32). In this study, the scFv antibody AD5 showed an approximately $10^{7} \mathrm{M}^{-1}$ affinity constant. Although scFv AD5 has an affinity to the antigen within the regular range, AD5 exhibits a slightly lower binding activity. The reason for this lower affinity of $\mathrm{scFv}$ antibodies may be related to the monovalent nature of the scFv molecule (33), and the non-immunized semi-synthetic antibody library we used (34). Although antibodies with moderate affinity $\left(10^{-7}-10^{-9} \mathrm{M}\right)$ may contribute to effective penetration into tumors and moderate retention on tumor cells (32), the moderate antibody affinity or specificity may be insufficient for diagnostic or certain therapeutic applications (27). In order to obtain higher affinity for $\mathrm{scFv}$, optimization of antibodies by either site-directed mutagenesis or chain shuffling is necessary (32). Using sitedirected mutagenesis of the variable light chain and variable heavy chain CDR3 regions, Adams et al (32) generated a series of affinity mutants from the original C6.5 scFv. These $\mathrm{scFv}$ antibodies bind to the same epitope of HER-2/neu with affinities ranging from $10^{-6}$ to $1.5 \times 10^{-11} \mathrm{M}(32,35)$. According to the intended application, the optimization of AD5 with appropriate affinity for antibody-based therapeutics will be carried out further using approaches similar to those outlined above.

In conclusion, cyclin D1 is a potential target for cancer prevention and treatment $(9,10)$. In this study, we successfully expressed and purified a novel scFv antibody AD5 with specific binding affinity to cyclin D1. This study undoubtedly provides a novel potential tool for targeting cyclin D1 in the therapy, diagnosis and prognosis of cancer.

\section{Acknowledgements}

This study was partially supported by grants from the National Natural Science Foundation of China (Nos. 31170882,
30972806 and 30200256), the Program for New Century Excellent Talents in University (NCET-09-0420) and the S\&T Development Planning Program of Jilin Province (Nos. 20111806 and 20090727) (to G.L.). We thank Professor Yan Wang of the Navy General Hospital, Beijing, China, for his assistance with the $\mathrm{scFv}$ antibody screening.

\section{References}

1. Sherr CJ: Mammalian G1 cyclins. Cell 73: 1059-1065, 1993.

2. Malumbres M and Barbacid M: Cell cycle, CDKs and cancer: a changing paradigm. Nat Rev Cancer 9: 153-166, 2009.

3. Deshpande A, Sicinski P and Hinds PW: Cyclins and CDKs in development and cancer: a perspective. Oncogene 24: 2909-2915, 2005.

4. Fu M, Wang C, Li Z, Sakamaki T and Pestell RG: Minireview: cyclin D1: normal and abnormal functions. Endocrinology 145: 5439-5447, 2004.

5. Musgrove EA, Caldon CE, Barraclough J, Stone A and Sutherland RL: Cyclin D as a therapeutic target in cancer. Nat Rev Cancer 11: 558-572, 2011.

6. Roy PG, Pratt N, Purdie CA, Baker L, Ashfield A, Quinlan P and Thompson AM: High CCND1 amplification identifies a group of poor prognosis women with estrogen receptor positive breast cancer. Int J Cancer 127: 355-360, 2010.

7. Yu Q, Geng Y and Sicinski P: Specific protection against breast cancers by cyclin D1 ablation. Nature 411: 1017-1021, 2001.

8. Choi YJ, Li X, Hydbring P, Sanda T, Stefano J, Christie AL, Signoretti S, Look AT, Kung AL, von Boehmer H and Sicinski P: The requirement for cyclin $\mathrm{D}$ function in tumor maintenance. Cancer Cell 22: 438-451, 2012.

9. Malumbres M: Cell cycle-based therapies move forward. Cancer Cell 22: 419-420, 2012.

10. Beroukhim R, Mermel CH, Porter D, et al: The landscape of somatic copy-number alteration across human cancers. Nature 463: 899-905, 2010.

11. Kim JK and Diehl JA: Nuclear cyclin D1: an oncogenic driver in human cancer. J Cell Physiol 220: 292-306, 2009.

12. Scott AM, Wolchok JD and Old LJ: Antibody therapy of cancer. Nat Rev Cancer 12: 278-287, 2012.

13. Elvin JG, Couston RG and van der Walle CF. Therapeutic antibodies: market considerations, disease targets and bioprocessing. Int J Pharm 440: 83-98, 2013.

14. Stewart CS, MacKenzie CR and Hall JC: Isolation, characterization and pentamerization of alpha-cobrotoxin specific single-domain antibodies from a naïve phage display library: preliminary findings for antivenom development. Toxicon 49: 699-709, 2007.

15. Wen S, Zhang X, Liu Y, Zhang QQ, Liu XJ and Liang JS: Selection of a single chain variable fragment antibody against ivermectin from a phage displayed library. J Agric Food Chem 58: 5387-5391, 2010.

16. Holliger P and Hudson PJ: Engineered antibody fragments and the rise of single domains. Nat Biotechnol 23: 1126-1136, 2005.

17. Dai H, Gao H, Zhao X, Dai L, Zhang X, Xiao N, Zhao R and Hemmingsen SM: Construction and characterization of a novel recombinant single-chain variable fragment antibody against white spot syndrome virus from shrimp. J Immunol Methods 279: 267-275, 2003.

18. Weisser NE and Hall JC: Applications of single-chain variable fragment antibodies in therapeutics and diagnostics. Biotechnol Adv 27: 502-520, 2009.

19. Zhou LH, Zhu X, Cao YH, Wang L, Chen Y, Du BR and Li GY: Construction of expression vector for anti-cyclin D1 intrabody AD5N and its inhibitory effects on cell proliferation of breast cancer. Chin J Immunol 24: 703-706, 2008.

20. Zhou LH, Zhu X, Cao YH, Chen Y, Tian Y, Wang L and Li GY: Effects of anti-cyclin D1 intrabody AD5N on HeLa cells of uterine cervix cancer. Chin J Clin Oncol 35: 942-944, 2008.

21. Qiao YY, Wang Y, Chen XS, Wang YX and Hua B: Construction of a large single-chain phage antibody library. Chin J Microbiol Immunol 24: 194-197, 2004.

22. Li GY, Zou DS and Zhou LH: Expression and purification of recombinant human cyclin D1 in E. coli BL21. J Jilin Univ 44: 839-843, 2006.

23. Beatty JD, Beatty BG and Vlahos WG: Measurement of monoclonal antibody affinity by non-competitive enzyme immunoassay. J Immunol Methods 100: 173-179, 1987. 
24. Ding Z, Wu CJ, Chu GC, et al: SMAD4-dependent barrier constrains prostate cancer growth and metastatic progression. Nature 470: 269-273, 2011

25. Bienvenu F, Jirawatnotai S, Elias JE, et al: Transcriptional role of cyclin D1 in development revealed by a genetic-proteomic screen. Nature 463: 374-378, 2010

26. Bartek J and Lukas J: DNA repair: Cyclin D1 multitasks. Nature 474: 171-172, 2011.

27. Ahmad ZA, Yeap SK, Ali AM, Ho WY, Alitheen NB and Hamid M: scFv antibody: principles and clinical application. Clin Dev Immunol 2012: 980250, 2012.

28. Zhu X, Wang D, Li S, Xiao Q, Tao K, Hu J, Cao W and Feng W: Expression of a humanized single-chain variable fragment antibody targeting chronic myeloid leukemia cells in Escherichia coli and its characterization. Int J Mol Med 29. 939-945, 2012.

29. Sushma K, Vijayalakshmi MA, Krishnan V and Satheeshkumar PK: Cloning, expression, purification and characterization of a single chain variable fragment specific to tumor necrosis factor alpha in Escherichia coli. J Biotechnol 156 238-244, 2010.

30. Yang T, Yang L, Chai W, Li R, Xie J and Niu B: A strategy for high-level expression of a single-chain variable fragment against $\mathrm{TNF} \alpha$ by subcloning antibody variable regions from the phage display vector pCANTAB 5E into pBV220. Protein Expr Purif 76: 109-114, 2011.
31. Abdolalizadeh J, Nouri M, Zolbanin JM, Baradaran B, Barzegari A and Omidi Y: Downstream characterization of anti-TNF- $\alpha$ single chain variable fragment antibodies. Hum Antibodies 21: 41-48, 2012.

32. Adams GP and Schier R: Generating improved single-chain Fv molecules for tumor targeting. J Immunol Methods 231: 249-260, 1999.

33. Yuan $\mathrm{W}$ and Parrish CR: Comparison of two single-chain antibodies that neutralize canine parovirus: analysis of an antibody-combining site and mechanisms of neutralization. Virology 269: 471-480, 2000.

34. Neri P, Shigemori N, Hamada-Tsutsumi S, Tsukamoto K, Arimitsu H, Shimizu T, Akahori Y, Kurosawa Y and Tsuji T: Single chain variable fragment antibodies against Shiga toxins isolated from a human antibody phage display library. Vaccine 29: 5340-5346, 2011.

35. Schier R, McCall A, Adams GP, Marshall KW, Merritt H, Yim M, Crawford RS, Weiner LM, Marks C and Marks JD: Isolation of picomolar affinity anti-c-erbB-2 single-chain Fv by molecular evolution of the complementarity determining regions in the center of the antibody binding site. J Mol Biol 263: 551-567, 1996. 